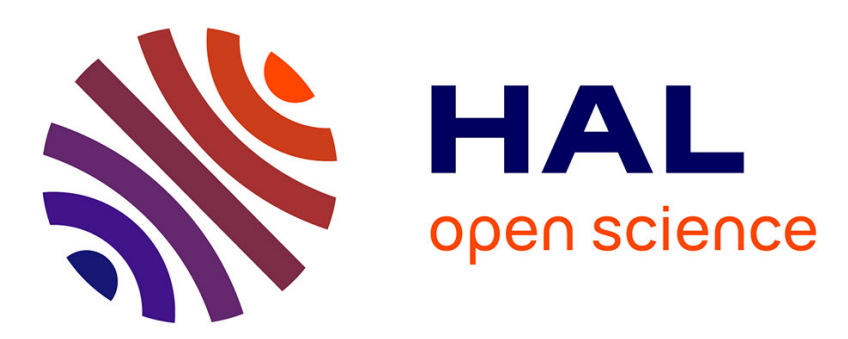

\title{
Application of sensitivity analysis in the life cycle design for the durability of reinforced concrete structures in the case of XC4 exposure class
}

\author{
van Loc Ta, Tristan Senga Kiessé, Stéphanie Bonnet, Anne Ventura
}

\section{- To cite this version:}

van Loc Ta, Tristan Senga Kiessé, Stéphanie Bonnet, Anne Ventura. Application of sensitivity analysis in the life cycle design for the durability of reinforced concrete structures in the case of XC4 exposure class. Cement and Concrete Composites, 2018, 87 (87), pp.53-62. 10.1016/j.cemconcomp.2017.11.024 . hal-01877119

\author{
HAL Id: hal-01877119 \\ https://hal.science/hal-01877119
}

Submitted on 19 Sep 2018

HAL is a multi-disciplinary open access archive for the deposit and dissemination of scientific research documents, whether they are published or not. The documents may come from teaching and research institutions in France or abroad, or from public or private research centers.
L'archive ouverte pluridisciplinaire HAL, est destinée au dépôt et à la diffusion de documents scientifiques de niveau recherche, publiés ou non, émanant des établissements d'enseignement et de recherche français ou étrangers, des laboratoires publics ou privés. 


\section{Application of sensitivity analysis in the life cycle design}

2 for the durability of reinforced concrete structures in

3 the case of $\mathrm{XC4}$ exposure class

4 Van-Loc TA ${ }^{a, 1}$, Tristan SENGA KIESSE ${ }^{\mathbf{b}}$, Stéphanie BONNET ${ }^{\mathrm{c}}$, Anne

5 VENTURA ${ }^{\mathrm{a}, \mathrm{d}}$

6 a Université de Nantes, GeM, Institut de Recherche en Génie civil et 7 Mécanique - CNRS UMR 6183 - Chaire Génie Civil Eco-construction,

8 France.

$9{ }^{b}$ UMR SAS, INRA, Agrocampus Ouest, 35000 Rennes, France.

$10{ }^{c}$ Université de Nantes, GeM, Institut de Recherche en Génie civil et 11 Mécanique - CNRS UMR 6183, France.

$12{ }^{d}$ Institut Français Transports Aménagement Réseaux (IFSTTAR - MAST 13 GPEM), France.

14 Abstract

15 The aim of this study is to develop a new design procedure for the durability 16 of the Reinforced Concrete (RC) structures in aggressive environments. The 17 study approach developed here includes: (i) a qualitative analysis phase to 18 characterize the design parameters and environmental exposure conditions of

\footnotetext{
${ }^{1}$ Corresponding author. Tel.: +332 72648761 ;

E-mail address : van-loc.ta@etu.univ-nantes.fr
} 
19 RC structures; (ii) a quantitative analysis phase, to establish the relationship

20 between service life and design parameters and environmental exposure 21 conditions using the service life prediction model firstly, and then to

22 determine the most influential design parameters on service life using 23 sensitivity analyses; and (iii) a final design phase, to design RC structures 24 using some favorable values of the most influential design parameters firstly, and then to compare the service life thus obtained with that of RC structures designed using a standardized approach. An application is also proposed on

27 simulated RC structure exposed to carbonation in Madrid (Spain). This RC 28 structure follows the recommendations of the European standard EN 206-1

29 for XC4 exposure class. The sensitivity analysis results are discussed in 30 detail including influence trends, importance ranking, non-monotonic effects 31 and parameter interaction influences. The most influential design parameters 32 obtained are cement strength class $\left(f_{\text {cem }}\right)$, water-to-cement ratio $(W / C)$ and 33 cement type $(C E M)$. By using $W / C$ of about $0.4, f_{\text {cem }}$ of about $52.5 \mathrm{MPa}$ and 34 CEM I cement type instead of their limiting value as recommended by EN 35 206-1, the service life of the RC structure is significantly improved.

36 Key words: Carbonation; Durability design; Corrosion; Service life. Morris 37 analysis, Sobol indices.

\section{1. Introduction}

39 In the literature, two basic approaches are proposed for the design of the 40 durability of Reinforced Concrete (RC) structures in aggressive 
41 environments [1]: a prescriptive approach and a performance-based 42 approach.

43 The prescriptive approach is primarily based on the acquired experience in 44 the durability performance of existing RC structures. Because experience is 45 generally insufficient to allow for the quantitative requirements, most of the 46 requirements for durability are formulated in a qualitative and empirical way. 47 In the case of reinforcing steel corrosion due to carbonation or chlorides, the 48 prescriptive approach defines an exposure class and subsequent prescriptions 49 including (i) concrete composition (a maximum water-to-cement ratio, a 50 minimum cement content and a cement type); (ii) a minimum 28-day 51 compressive strength of the concrete; and (iii) a minimum concrete cover 52 depth for service life design [2] [3].

53 The key feature of the performance-based approach is to assess relevant 54 concrete material properties using some relevant test methods or service life 55 prediction models. This approach can be used to formulate requirements as 56 regards material properties and structure dimensions. In the case of corrosion 57 of reinforcing steel due to carbonation [4] [1] [5] or chlorides [6] [7] [8], the 58 estimation of the deterioration evolution depending on expected influential 59 parameters is mostly performed by applying a probabilistic approach. This 60 estimation makes it possible to formulate requirements for the structural 61 responses depending on the service life design [3]. Then, durability design 62 can be completed in two ways: (i) using a fully probabilistic method, for 63 which the concrete cover depth and the diffusion coefficient of $\mathrm{CO}_{2}$ or 
64 chlorides are usually considered as main probabilistic design parameters for

65 the required service life design and the reliability level [4] [1] [5] [6] [7] [8]; and (ii) using the partial factor method to determine the characteristic values

67 and the partial factors for the design parameters [4] [1] [7].

The strength of the prescriptive approach lies in its flexibility to account

69 for experience and its easy application. The obvious weakness of this

70 approach is that: (i) a simple set of general prescriptions cannot be optimal

71 for all the different parts of a structure exposed to different levels of aggressiveness depending on the structure areas [9]; (ii) our understanding of service durability performance of the structure at the design stage must be improved [1]; and (iii) it does not encourage the use of novel materials for durability design. The strength of the performance-based approach, on the other hand, is its relevance for the durability responses so that service life design can be carried out in a more scientific and reliable way. However, two main difficulties must be faced: (i) a better understanding of the deterioration mechanisms must combine the results of both the scientific research with

80 long-term in-situ observations; and (ii) the uncertainty associated with

81 deterioration mechanisms must be properly taken into consideration in the design process. This last issue can be solved by carrying out a sensitivity analysis of service life in relation to modeling parameters. The Sensitivity

84 Analysis (SA) is the study of how the uncertainty of a mathematical model 85 or system (numerical or other systems) results can be apportioned to different 86 sources of uncertainty and variability of the input parameters [10]. In the 
87 literature, many studies present the SA of the simplified diffusion-based 88 corrosion initiation model of RC structures exposed to chlorides. This 89 analysis is conducted to identify, among the different parameters like

90 concrete cover depth, chloride diffusion coefficient, chloride threshold level,

91 and chloride concentration at the surface, those which are the most 92 significant [11] [12]. Other studies describe the SA of corrosion rate 93 prediction models [13] or simplified carbonation models [14] conducted to 94 classify the different influences of the input parameters. Some authors use the "One At a Time (OAT)" SA method [11] [12], which provides some semi96 qualitative sensitivity information by varying one parameter at a time while 97 keeping the others constant. Sensitivity is observed graphically. Other 98 authors use the SA method based on the regression analysis [13] [14]. This 99 method quantifies the effect of the input parameters on the model results.

100 It is sometimes difficult to distinguish between prescriptive or 101 performance-based design approaches. For instance, if the existing RC 102 structures on a given project site have achieved the objective set by service 103 life design, then the durability design of new RC structures can rely on the 104 rational analysis of the durability measurements carried out on these RC 105 structures. Consequently, determining whether structure design is 106 specifically based on the prescriptive or the performance-based approach is 107 difficult, in this case. The experimental data on the durability performance 108 of the structures thus collected must be integrated into the different phases 109 of the performance-based approach to determine the preliminary dimensions 
110 of the structure [3]. Thus, both approaches are useful as regards durability

111 design and are complementary methods in the global design process.

112 The present paper reports a study conducted to develop a new design

113 procedure for the durability of the RC structures in aggressive environments.

114 The procedure discussed here is the result of the combination of both

115 prescriptive and performance-based approaches. Qualitative and quantitative

116 SA methods are integrated into the design procedure to determine durability

117 action levers (refer to definition of "action levers" in Appendix). These are

118 used to design the best durable RC structure.

119 The new design procedure for the durability of RC structures in aggressive

120 environments is presented in Section 2. An application of this procedure to

121 a simulated RC structure exposed to carbonation in Madrid (Spain) is

122 described in Section 3. Some recommendations for the durability design

123 according to EN 2016-1 for XC4 exposure class are discussed in Section 4.

124 2. Development of the new durability design procedure

125 The durability design procedure proposed here includes: (1) a qualitative

126 analysis, (2) a quantitative analysis, and (3) a final design procedure (Figure

127 1). The purpose of the qualitative analysis is to determine the preliminary

128 dimensions of a RC structure at a general level within the context of

129 aggressive environments. It also includes the characterizations of the design

130 parameters and the environmental exposure conditions. This analysis is

131 carried out using a prescriptive approach. The quantitative analysis aims at 
132 establishing a relationship between the aggressive environment and the

133 service life of structure using a service life prediction model [4]. The purpose

134 of the quantitative analysis is to determine the action levers by applying the

135 SA method to the service life prediction model. The final design phase

136 consists in using the action levers to redesign the RC structure properties in

137 order to achieve the longest service life possible. This phase also includes a

138 comparison between the service life of a structure designed using the

139 procedure proposed here and that of a structure designed using the

140 recommended limiting values of EN 206-1 [15].

141

\begin{tabular}{|l|l|}
\hline \multicolumn{1}{|c|}{ 1/ QUALITATIVE ANALYSIS } \\
3/ FINAL DESIGN \\
Of input parameters).
\end{tabular}

142 Figure 1. Design procedure for durability of $R C$ structures in aggressive environments.

144 In order to determine the action levers, suitable SA methods must be 145 selected. They must provide the trend of action levers in relation to the 146 service life, the quantization of their influence and the interactions with other 
147 parameters. Thus, the SA methods used in the previous studies [11] [12] [13]

148 [14] are not relevant in this context. Consequently, a combination of two SA

149 methods, Sobol's quantitative method [16] and Morris' qualitative method

150 [17] is chosen. This combination has been previously used for the same

151 purpose in environmental design using Life Cycle $\underline{\text { Assessment (LCA) [18] }}$

152 [19]. It can provide complementary information on the influence of the input

153 parameters on the model results in the decision-making process. Sobol's

154 method is used to quantify the input parameters contribution to model result

155 variations. Morris' method, on the other hand, provides additional

156 information on the trend of the input parameters. Both methods require that

157 all the input parameters are independent of one another. Both methods are

158 summarized in the next subsections.

\subsection{Sobol's quantitative sensitivity analysis}

160 Sobol's method [16] is based on the analysis of the variance decomposition

161 of the model $f$ in order to quantify the contribution of variability of the input

162 parameter $X_{j}$ to the total variance of the output $Y$. The individual contribution

163 of input parameter $X_{j}$ is measured using the first order sensitivity index $\left(S_{j}\right)$

164 such as:

$$
S_{j}=\frac{\operatorname{Var}\left(\mathbb{E}\left[Y \mid X_{j}\right]\right)}{\operatorname{Var}(Y)}
$$

165 where: $\operatorname{Var}\left(\mathbb{E}\left[Y \mid X_{j}\right]\right)$ is the conditional variance of $Y$ produced by the

166 variation of $X_{j}, \operatorname{Var}(Y)$ is the total variance of $Y$. 
167 The individual Sobol indices lie in the interval [0-1]. Moreover, the overall 168 output sensitivity to the parameter $X_{j}$ (i.e., including first and higher order

169 effects (interaction) of $X_{j}$ ) can be measured using the total sensitivity index $170\left(S_{T_{j}}\right)[20]$ as:

$$
S_{T j}=1-\frac{\operatorname{Var}\left(\mathbb{E}\left[Y \mid X_{\neq j}\right]\right)}{\operatorname{Var}(Y)}
$$

171 where: $\operatorname{Var}\left(\mathbb{E}\left[Y \mid X_{\neq j}\right]\right)$ is the conditional variance of $Y$ produced by the

172 variation of all the input parameters except $X_{j}$.

173 Sobol's method requires to have characterized the Probability Density 174 Function (PDF) of each input parameter. The Monte Carlo simulations are 175 carried out by varying simultaneously all the input parameters according to 176 their PDF and by calculating the associated model results. In this study, $S_{j}$ 177 and $S_{T_{j}}$ are calculated.

\section{2.2. Morris's qualitative sensitivity analysis}

179 Morris' method [17] is one of the most popular screening method, which 180 consists in developing a randomized experimental design process by varying one parameter while keeping the others constant (OAT method) over a certain number of repetitions $k(k=1,2, \ldots, r)$. Then, the variation coefficients, called

183 the elementary effects $\left(\mathbb{E E}_{j}^{(k)}\right)$, are obtained as: 


$$
\mathbb{E E}_{j}^{(k)} \approx \frac{f\left(\mathbb{X}^{(k)}+e_{j} \cdot \Delta\right)-f\left(\mathbb{X}^{(k)}\right)}{\Delta}
$$

184 where: $\Delta$ is a pre-defined step, $e_{j}$ is a vector of zero but with $j$-th equal \pm 1 .

185 The mean value $\left(\mu_{j}\right)$ of the elementary effects is calculated to determine the

186 trend of input parameter $X_{j}$. The algebraic sign of $\mu_{j}$ indicates increasing 187 (positive sign) or decreasing (negative sign) trends of the model output 188 related to $X_{j}$. The standard deviation value $\left(\sigma_{j}\right)$ of the elementary effects is 189 the measure of the sum of all the interactions of $X_{j}$ with the other parameters 190 and of all non-linear influences. We find:

$$
\begin{aligned}
\mu_{j} & =\frac{1}{r} \sum_{k=1}^{r} \mathbb{E E}_{j}^{(k)} \\
\sigma_{j} & =\sqrt{\frac{1}{r-1} \sum_{k=1}^{r}\left(\mathbb{E E}_{j}^{(k)}-\mu_{j}\right)^{2}}
\end{aligned}
$$

191 In the case of non-monotonic functions, the elementary effects can have an 192 opposite sign for the considered repetition, which can result in a $\mu_{j}$ close to 193 zero if the parameter is influential. In order to prevent this, Campolongo et 194 al. [21] recommend to use the mean value of the absolute value $\left(\mu_{j}^{*}\right)$ of the 195 elementary effects rather than the usual $\mu_{j}$.

$$
\mu_{j}^{*}=\frac{1}{r} \sum_{k=1}^{r}\left|\mathbb{E E}_{j}^{(k)}\right|
$$


196 The information about the algebraic sign of $\mu_{j}$ is lost when using $\mu_{j}^{*}$.

197 However, it is a good indicator for the assessment of the importance of the

198 input parameters in relation to each other. Morris' method requires a local

199 interval range (minimum and maximum value) for each input parameter. The

200 number of repetitions $r$ ranges from 4 to 10 [22]. In this study, $\mu_{j}, \mu_{j}^{*}$ and $\sigma_{j}$

201 are calculated.

202 Throughout the rest of the work, Morris and Sobol methods serve to identify 203 input parameters that are major contributors to the variability of service life.

204 More specifically, the controllable parameters related to technological 205 aspects (e.g., concrete mix, size of structure), i.e., the "technological 206 parameters", are considered as action levers if they are major contributors to 207 the service life.

\section{2.3. Identification of action levers using sensitivity indices}

209 Based on the Sobol indices, the technological parameters are identified as 210 action levers, if the value of $S_{j}$ is higher than $10 \%$. Moreover, if the value of $211 S_{j}$ is lower than $10 \%$ but the difference $\left(S_{T_{j}}-S_{j}\right)$ is high, i.e., assumed to be 212 greater than $10 \%$, they can also be considered as potential action levers [18] 213 [19]. This means that parameter $X_{j}$ is not individually influential but has a 214 non-negligible global contribution because of its interaction with the other 215 parameters. As regards the Morris indices, the parameters with a higher $\mu_{j}^{*}$ 216 are considered as potential action levers [17]. If the parameters satisfy the

217 condition $\sigma_{j} \geq\left|\mu_{j}\right|$, they are considered to have a non-monotonic effect. In 
218 contrast, non-influential input parameter $X_{j}$ is assumed to have indices $S_{T_{j}}$

219 lower than $10 \%$ and $\mu_{j}^{*}$ low in relation to other indices $\mu_{i, i \neq j}^{*}$ of input 220 parameters $X_{i, i \neq j}$. Recall that Morris indices $\mu_{j}^{*}$ and $\mu_{j}$ have the same order of 221 magnitude than the model response while the first order Sobol indices $S_{j}$ are 222 normalized and lie in the interval [0-1].

\section{3. Case study}

\section{3.1. Presentation of the case study}

225 The case study studied here consists of a RC structure subjected to 226 carbonation. The structure is assumed to be located in Madrid (Spain)

227 because this location presents optimal environmental conditions for 228 carbonation of concrete [23] [24]. Madrid, indeed, is a place with a high level 229 of carbon dioxide [25] and with an average relative external humidity of 230 about 0.56 [26]. The considered structure follows the recommendations of 231 EN 206-1 for XC4 exposure class [15]: concrete is exposed to the air and the 232 structure is not sheltered from rain. Carbonation is the only alteration 233 phenomenon of RC structure considered in this paper. The objective here is 234 to identify the action levers affecting service life to obtain the longest service 235 life possible by setting the identified action levers at their most favorable 236 value.

237 The service life of a structural component is the period after construction, 238 during which all the structure properties, when routinely maintained, are 
239 higher than the minimum acceptable values [2]. Tuutti [27] proposed a 240 simplified model for predicting the service life of RC structures, considering

241 the degradation due to carbonation induced corrosion. Service life is divided

242 into two periods: initiation period and propagation period as shown in Figure

243 2. There are two periods because the mechanisms involved are different in

244 physical-chemical terms. The initiation period corresponds to the penetration 245 of $\mathrm{CO}_{2}$ into the concrete cover until the carbonation front reaches the 246 reinforced layer. The propagation period includes (i) steel corrosion; (ii) 247 cross section loss; (iii) concrete surface cracking; and (iv) spalling of 248 concrete cover.

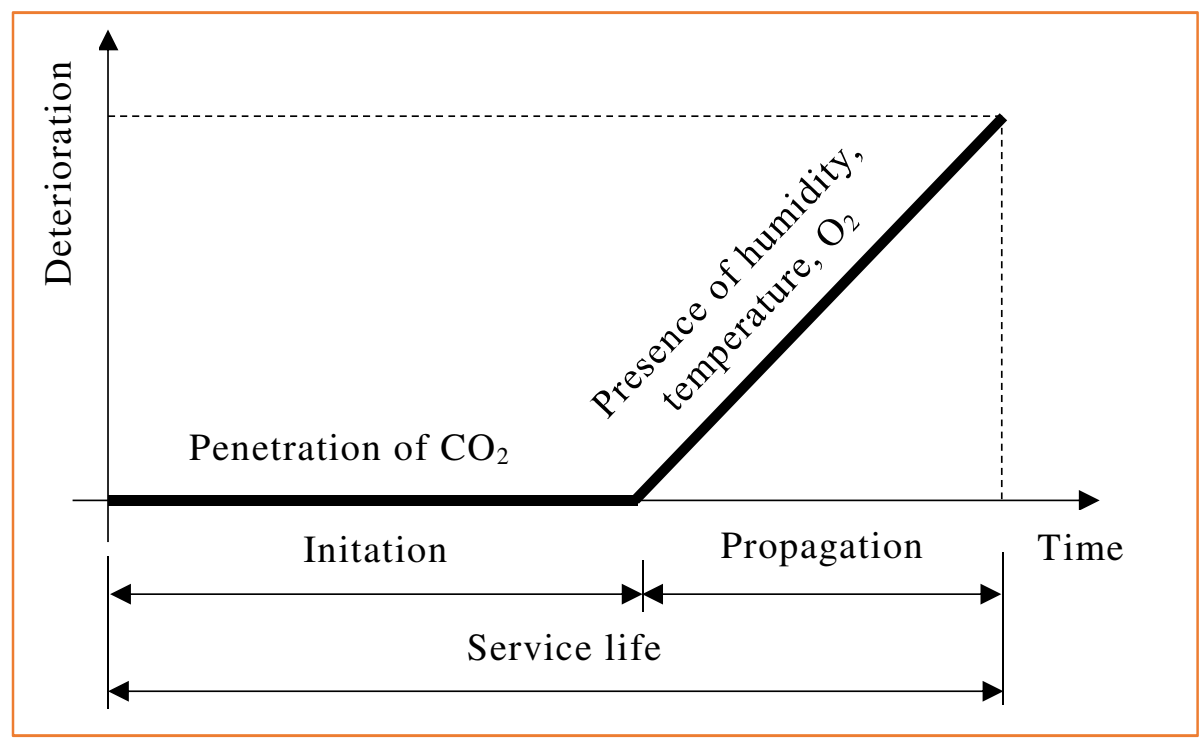
Figure 2. Tuuti's service life prediction model [27].

251 Our case study deals with the initiation period only. The service life of RC 252 structure is limited to the corrosion initiation period. Thus, a model for the 
253 initiation period is required: that model calculates at any time the 254 carbonation depth within concrete.

\subsection{Qualitative analysis: characterization of input parameters}

256 The service life considered here is predicted using the carbonation model

257 recently developed by Ta et al. [28] (Figure 3). This carbonation model is 258 validated using data from the literature on short and long-term natural 259 carbonation exposure conditions. Most of the experimental data concern

260 CEM I, CEM II, CEM III cement types. The prediction of this carbonation 261 model for estimation of carbonation depth is more accurate than Papadakis' 262 model [29] and Yang's model [30]. This model takes many influencing 263 design parameters of the carbonation process into account and predicts the 264 natural carbonation depth. It is based on the analytical solution of Fick's law 265 given by:

$$
x=\sqrt{\frac{2 \times D_{\mathrm{CO}_{2}} \times \mathrm{CO}_{2}}{a}} \times \sqrt{t}
$$

266 where: $x(m)$ is the carbonation depth within concrete, $D_{\mathrm{CO}_{2}}\left(\mathrm{~m}^{2} / \mathrm{s}\right)$ is the $\mathrm{CO}_{2}$

267 diffusion coefficient of concrete, $\mathrm{CO}_{2}\left(\mathrm{~kg} / \mathrm{m}^{3}\right)$ is the $\mathrm{CO}_{2}$ concentration in the 268 atmosphere, a $\left(\mathrm{kg} / \mathrm{m}^{3}\right)$ is the amount of $\mathrm{CO}_{2}$ absorbed in a unit volume of concrete, $t(s)$ is the exposure time. 


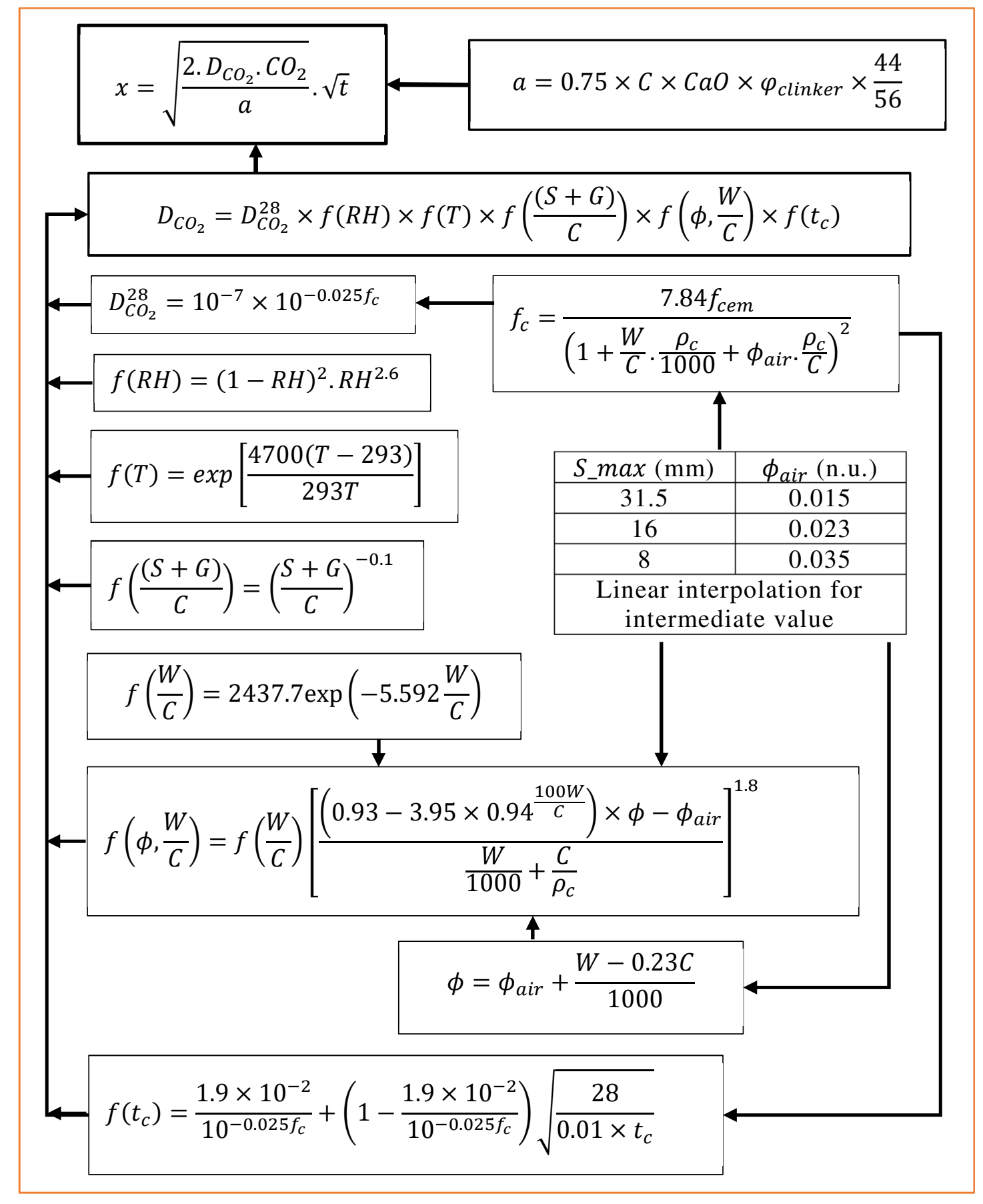
detailed in the text).

273 When the carbonation depth is equal to the concrete cover depth $(d)$, i.e., $274 x=d$, the corrosion initiation period ends. The steel reinforcement could be 
275 then corroded with the presence of $\mathrm{O}_{2}$, humidity and temperature as defined

276 by Tuuti's service life prediction model (Figure 2 ). Service life $\left(t_{\text {ser }}\right)$ can be 277 written as:

$$
t_{s e r}=\frac{d^{2} \times a}{2 \times D_{C_{2}} \times C O_{2}}
$$

278 The purpose then is to design a concrete structure with a maximum service 279 life value $t_{\text {ser }}$.

280 Many parameters are required for the calculation of $D_{\mathrm{CO}_{2}}$ and $a$ as shown in 281 Figure 3. For the application of Sobol and Morris' methods to the 282 determination of the sensitivity of $t_{\text {ser }}$ to input parameters, we use only the 283 expression of $D_{\mathrm{CO}_{2}}$ and $a$ in relation to the independent parameters. An 284 independent parameter does have a relationship with other independent 285 parameters. The dependent parameters are expressed through the independent 286 parameters. The time dependency of the input parameters is not taken into 287 account. Consequently, the expression of $t_{\text {ser }}$ takes the form:

$$
t_{\text {ser }}=f\left(C, W / C, S / G, S \_\max , C E M, f_{\text {cem }}, d, t_{c}, T, R H, C O_{2}\right)
$$

288 or

$$
t_{\text {ser }}=f\left(X_{1}, X_{2}, X_{3}, X_{4}, X_{5}, X_{6}, X_{7}, X_{8}, X_{9}, X_{10}, X_{11}\right)
$$

289 where: $C\left(\mathrm{~kg} / \mathrm{m}^{3}\right.$ of concrete) is the amount of cement content, $W / C$ (n.u.) 290 (n.u. = no unit) is the water-to-cement ratio, $S / G$ (n.u.) is the sand-to-gravel ratio, $S \_\max (\mathrm{mm})$ is the maximum aggregate size, CEM (n.u.) is the cement 
type, $f_{c e m}(\mathrm{MPa})$ is the cement strength class, $t_{c}$ (days) is the initial curing period, $T(K)$ is the ambient temperature, $R H$ (n.u.) is the relative external

294 humidity.

295 The input parameters, including the technological and environmental 296 parameters (refer to definition of "technological and environmental 297 parameters" in Appendix), characterized by determining the variability range 298 and the PDF of each parameter as summarized in Table 1. The technological 299 parameters are characterized by the limiting values recommended by EN 206-

3001 [15] for XC4 exposure class and the statistical analysis of the studies 301 addressing the problem of concrete carbonation found in the literature. To 302 provide the action levers, a uniform (discrete or continue) distribution is

303 usually set for the technological parameters because they are chosen by the 304 designer. Thus, all the values within the distribution interval are considered 305 equally probable. The interval is determined by minimum and maximum 306 values.

307 The environmental parameters are characterized from weather data [26], 308 which include the ambient temperature $(T)$ and the relative external humidity $309(\mathrm{RH})$. The $\mathrm{CO}_{2}$ concentration in the atmosphere $\left(\mathrm{CO}_{2}\right)$ is taken from [25].

310 Table 1. Input parameter characterization.

\begin{tabular}{llll}
\hline Parameter Unit $\quad \underline{\text { Probability }} \underline{\text { Density }}$ Function (PDF) & Reference \\
\hline Technological parameters & \\
\hline Group 1: concrete mix & \\
\hline
\end{tabular}




\begin{tabular}{|c|c|c|c|c|}
\hline$X_{1}$ & $\bar{C}$ & $\mathrm{~kg} / \mathrm{m}^{3}$ & $\mathcal{U}(\min =300 ;$ mean $=404.5 ; \max =509)$ & {$[15]$} \\
\hline$X_{2}$ & $W / C$ & n.u. & $\mathcal{U}(\min =0.4 ;$ mean $=0.45 ; \max =0.5)$ & {$[15]$} \\
\hline$X_{3}$ & $S / G$ & n.u. & $\mathcal{U}(\min =0.5 ;$ mean $=1.3 ; \max =2.1)$ & \\
\hline$X_{4}$ & $S_{-} \max$ & $\mathrm{mm}$ & $\mathcal{U}(\min =20 ;$ mean $=26 ; \max =32)$ & {$[15]$} \\
\hline \multicolumn{5}{|c|}{ Group 2: cement } \\
\hline$X_{5}$ & CEM & n.u. & $d \mathcal{U}(10$ cement types $)$ & {$[15]$} \\
\hline$X_{6}$ & $f_{\text {cem }}$ & $\mathrm{MPa}$ & $d \mathcal{U}(3$ strength classes $)$ & {$[15]$} \\
\hline \multicolumn{5}{|c|}{ Group 3: concrete cover depth and initial curing period } \\
\hline$X_{7}$ & $d$ & $\mathrm{~m}$ & $\mathcal{U}(\min =0.05 ;$ mean $=0.065 ; \max =0.08)$ & {$[31][32]$} \\
\hline$X_{8}$ & $t_{c}$ & days & $\mathcal{U}(\min =1 ;$ mean $=2 ; \max =3)$ & {$[33]$} \\
\hline \multicolumn{5}{|c|}{ Environmental parameters } \\
\hline$\overline{X_{9}}$ & $T$ & $\overline{\mathrm{K}}$ & $\begin{array}{c}\operatorname{tr} \mathcal{N}(\text { mean }=287.4 ; \mathrm{CoV}=0.03 \\
\min =272.4 ; \max =309.1)\end{array}$ & {$[26]$} \\
\hline$X_{10}$ & $R H$ & n.u. & $\begin{array}{c}\operatorname{tr} \mathcal{N}(\text { mean }=0.56 ; \mathrm{CoV}=0.33 \\
\min =0.2 ; \max =0.88)\end{array}$ & [26] \\
\hline$X_{11}$ & $\mathrm{CO}_{2}$ & $\mathrm{ppm}$ & $\begin{array}{l}\operatorname{tr} \mathcal{N}(\text { mean }=380 ; \mathrm{CoV}=0.05 \\
\quad \min =304.6 ; \max =456.8)\end{array}$ & {$[25]$} \\
\hline
\end{tabular}

\section{Notes:}

1. $\mathrm{CoV}=\underline{\text { Coefficient }}$ of $\underline{\text { Variation; }} \operatorname{tr} \mathcal{N}=$ truncated Normal distribution; $\mathcal{U}$

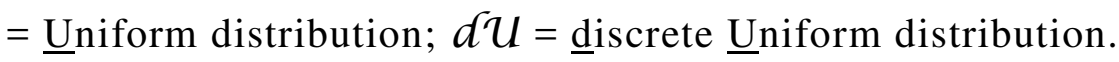

2. The variability range of $X_{1}, X_{2}$ and $X_{3}$ parameters also comes from the statistical analysis conducted by some experimental investigations found in the literature (detailed in the text).

\section{Group 1: concrete mix}

312 The requirements for concrete of EN 206-1 [15] for XC4 exposure class are

313 a maximum water-to-cement ratio $(W / C)$ of about 0.5 , a minimum amount of 
314 cement content $(C)$ of about $300 \mathrm{~kg} / \mathrm{m}^{3}$ and maximum aggregate size $\left(S \_\right.$max $)$

315 within the range 20-32 mm. Previous studies [4] [34] [35] [36] reveal that (i)

316 CEM I cement type concrete with a water-to-cement ratio $(W / C)$ lower than

3170.4 has very high carbonation resistance; and (ii) concrete using CEM I

318 cement type has higher carbonation resistance than the other cement types

319 containing additions. In this work, we thus assume the minimum $W / C$ of

320 about 0.4 for cement types considered in order to observe the carbonation

321 phenomenon; however, the carbonation phenomenon can appear for $W / C$

322 values lower than 0.4 for other cement types. Moreover, concrete casted with

323 such $W / C$ is uncommon. Based on the statistical analysis of seventeen

324 experimental investigations on concrete carbonation [37] [5] [38] [39] [40]

325 [41] [42] [43] [44] [45] [24] [46] [47] [48] [1] [49] [50], the maximum

326 cement content $(C)$ is about $509 \mathrm{~kg} / \mathrm{m}^{3}$ and the sand-to-gravel ratio $(S / G)$

327 varies between 0.5 and 2.1 .

\section{Group 2: cement}

329 In the carbonation model proposed by Ta et al. [28], the cement type (CEM)

330 is considered through the following three parameters: amount of Portland

331 clinker inside cement, amount of calcium oxide per weight of cement and

332 cement density. Therefore, among the 27 cement products presented in [51],

333 ten cement types are considered: CEM I; CEM II/A; CEM II/B; CEM III/A;

334 CEM III/B; CEM III/C; CEM IV/A; CEM IV/B; CEM V/A; and CEM V/B.

335 The characteristics of these cements are presented in Appendix (Table A1). 
336 Cement strength class $\left(f_{\text {cem }}\right)$ of all these cement types is available for strength

337 classes of $32.5 \mathrm{MPa}, 42.5 \mathrm{MPa}$ and $52.5 \mathrm{MPa}$.

\section{Group 3: concrete cover depth and initial curing period}

339 The concrete cover depth $(d)$ must have a minimum thickness to protect the

340 steel reinforcements from the $\mathrm{CO}_{2}$ attack and to prevent the corrosion of steel

341 reinforcements [52]. This design parameter varies according to the exposure

342 class, the quality of construction and the intended service life [52].

343 Combined to the requirements for concrete of EN 206-1 [15] for XC4

344 exposure class, the minimum recommended concrete cover depth $(d)$ ranges

345 from about $0.05 \mathrm{~m}$ [31] to $0.08 \mathrm{~m} \mathrm{[32]} \mathrm{for} \mathrm{structure} \mathrm{design} \mathrm{with} \mathrm{an} \mathrm{expected}$

346 100-year service life. Consequently, $d$ can vary between 0.05 and $0.08 \mathrm{~m}$ in

347 this study.

348 Because of a limited construction time, the initial curing period $\left(t_{c}\right)$ varies 349 between 1 day and 3 days [33].

\section{3.3. Quantitative analysis}

\subsubsection{Service life prediction and sensitivity analysis}

$352 E q .(10)$ is used to establish the relationship between the service life $\left(t_{s e r}\right)$ and the input parameters $X_{j}$ presented in Table 1 . In Sobol' method, the $t_{s e r}$

354 values are simulated using Eq. (10) by varying all input parameters 355 simultaneously according to their PDF (Table 1). 
356 The first order Sobol sensitivity index $\left(S_{j}\right)(E q .(1))$ and the total Sobol

357 sensitivity index $\left(S_{T_{j}}\right)(E q .(2))$ are calculated as described in Section 2.3.

358 They are calculated by means of a bootstrap method with 500 replications

359 from a half-sample $(5,000)$ taken from an initial sample of about 10,000 as

360 recommended in [18].

361 In Morris' method, the $t_{\text {ser }}$ values are simulated using Eq. (10) by varying

362 each input parameter one at a time. Then the mean value $\left(\mu_{j}\right)(E q .(4))$,

363 standard deviation value $\left(\sigma_{j}\right)(E q .(5))$ and mean value of the absolute value

$364\left(\mu_{j}^{*}\right)(E q .(6))$ of the elementary effects are calculated as described in Section

365 2.3. They are calculated by means of discretization of the input parameters

$366 X_{j}$ in 10 values with a prescribed number of trajectories of about 30 as

367 recommended in [18].

\subsubsection{Determination of the action levers}

369 Our results shown in Figure 4 are related to the case study. It is important

370 to note that SA results depend on both PDF of input parameters given in

371 Table 1 and on carbonation model chosen.

$372 \quad$ Figure 4 displays the SA results. 


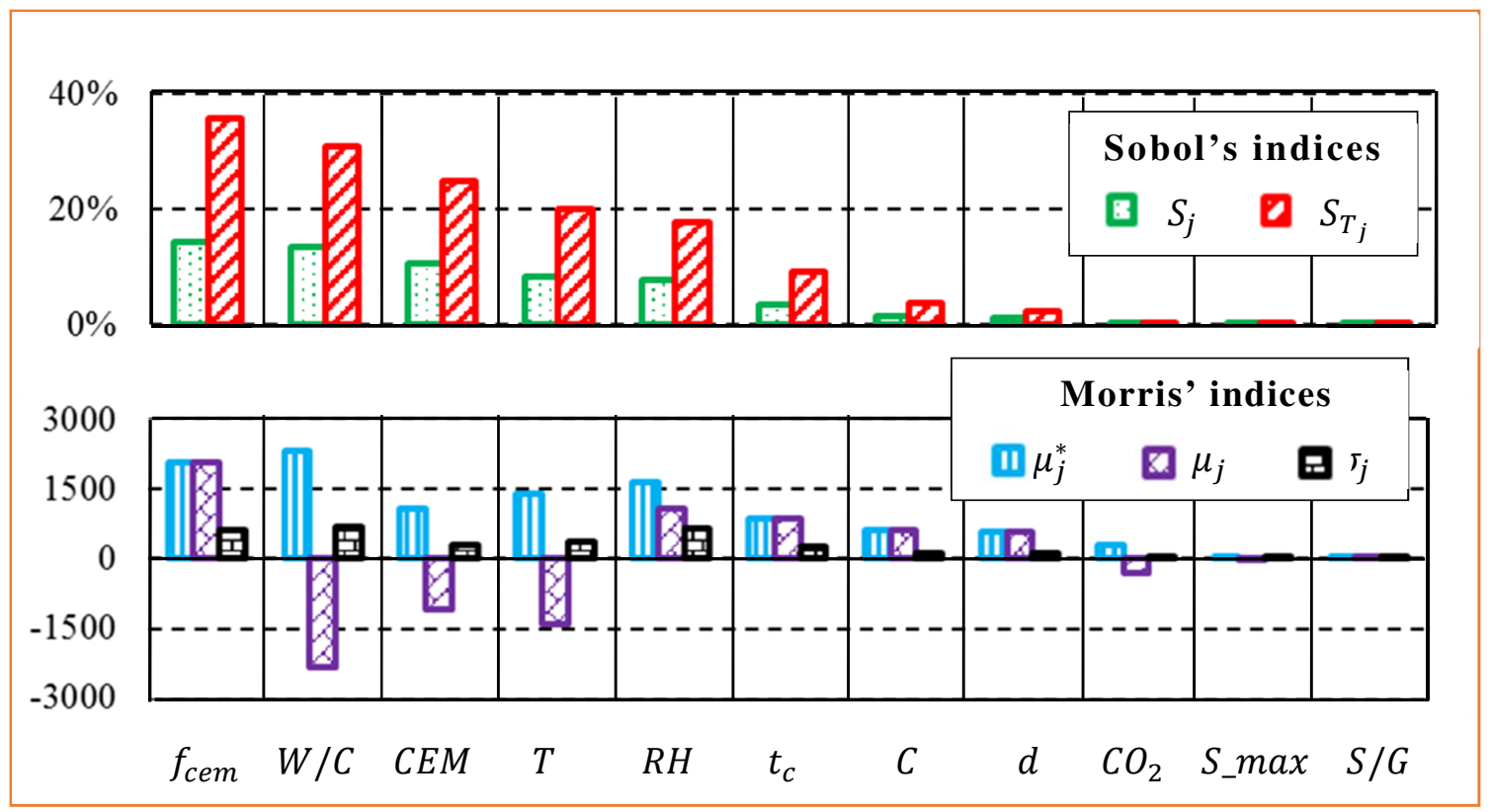

Figure 4 shows that cement strength class $\left(f_{\text {cem }}\right)$, water-to-cement ratio $376(W / C)$, cement type $(C E M)$, ambient temperature $(T)$ and relative external 377 humidity $(R H)$ (in descending rank) are the most influential parameters 378 because their $S_{T_{j}}$ and $\mu_{j}^{*}$ values are the highest. The difference $S_{T_{j}}-S_{j}$ is 379 around $22 \%$ for cement strength class $\left(f_{\text {cem }}\right), 17 \%$ for water-to-cement ratio $380(W / C), 14 \%$ for cement type $(C E M), 12 \%$ for ambient temperature $(T)$ and $381 \quad 10 \%$ for relative external humidity $(R H)$. This means that their interactions 382 with the other parameters are important. Parameters $f_{c e m}, W / C$ and $C E M$ are 383 considered the most influent with a $S_{j}$ value above $10 \%$. They are thus 384 technological parameters (i.e., controllable parameters) identified as action 385 levers. $T$ and $R H$ are environmental parameters (uncontrollable parameters) that are uncertain. The less-influential parameters $\left(S_{T_{j}}<10 \%\right.$ and low $\left.\mu_{j}^{*}\right)$ are 
387 initial curing period $\left(t_{c}\right)$, cement content $(C)$, concrete cover depth $(d), \mathrm{CO}_{2}$

388 concentration in the air $\left(\mathrm{CO}_{2}\right)$, maximum aggregate size $\left(S_{-}\right.$max $)$and sand-to-

389 gravel ratio $(S / G)$. Based on the algebraic sign of $\mu_{j}$, we observe that an

390 increase in $R H, C, d, t_{c}$, and $S / G$ and a decrease in $W / C, S \_m a x, T$, and $C_{2}$

391 result in the increase of $t_{s e r}$. All parameters have $\sigma_{j} / \mu_{j}^{*}$ within the interval

$392[0.19-0.39]$. It indicates that the effects between parameter are monotonic.

393 Because $f_{\text {cem }}$ and $C E M$ are discrete parameters, their algebraic sign of $\mu_{j}$ is

394 not significant. Finding favorable value requires testing all of the values of

$395 f_{\text {cem }}$ and CEM. The simulation results are displayed in Figure 5 . We plot the

396 service life on log scale versus clinker content. The service life is represented

397 by its mean value and standard deviation.

398

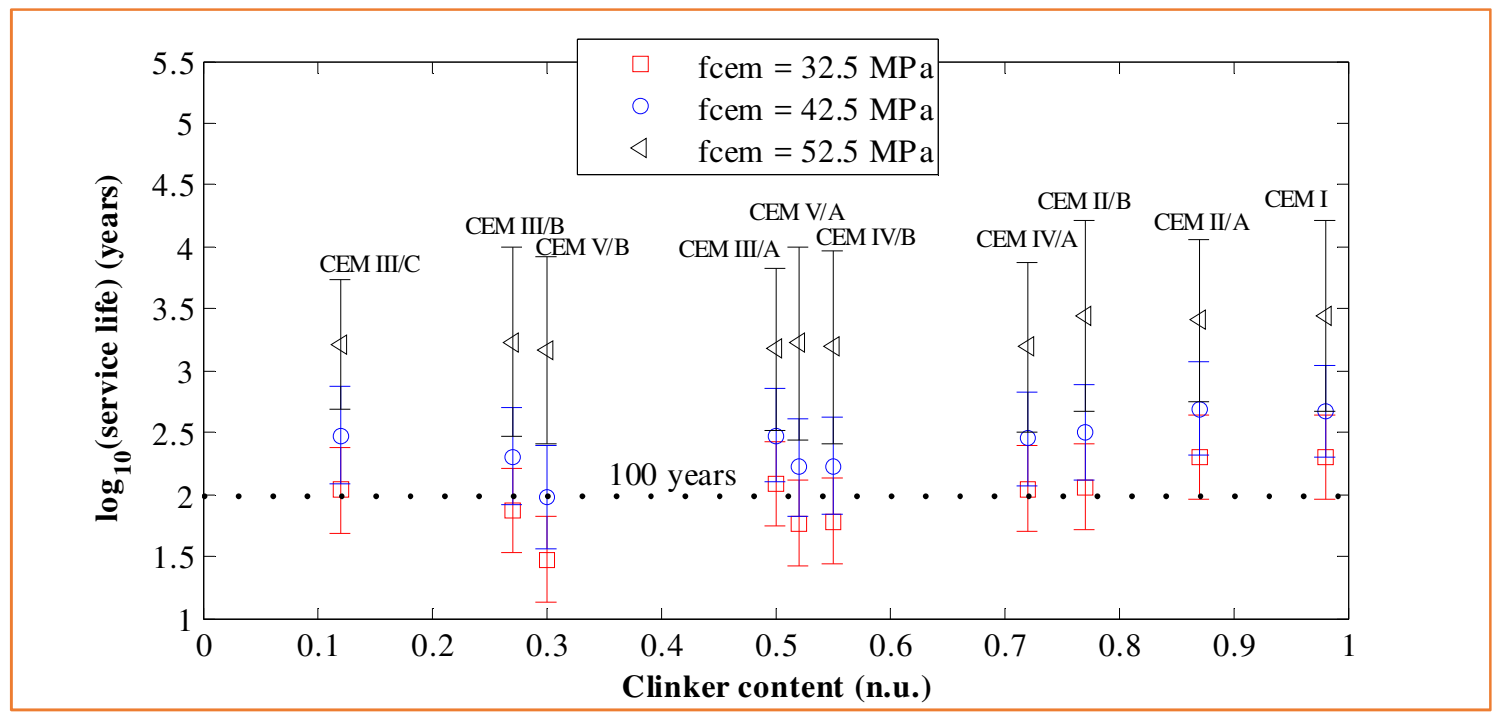

399

Figure 5. Comparison of service lives of cement strength classes and 
401 The highest service life is obtained with cement strength class $\left(f_{\text {cem }}\right) 52.5$ $402 \mathrm{MPa}$, followed by $42.5 \mathrm{MPa}$ and $32.5 \mathrm{MPa}$. The CEM I and CEM II/B cement 403 types are the most favorable to increase the service life with $f_{\text {cem }} 52.5 \mathrm{MPa}$. 404 The CEM II/B has lower environmental impacts. These findings are in line 405 with previous study [38]. For both $f_{\text {cem }} 42.5$ and $52.5 \mathrm{MPa}$ we found that 406 service life is higher than 100 years whatever the cement type. However, 407 none of the service lives considering standard deviation obtained with $f_{\text {cem }}$ $408 \quad 32.5 \mathrm{MPa}$ is higher than 100 years.

\subsubsection{Comparison of the sensitivity analysis results to the}

\section{literature}

411 This section compares our SA results with the literature. Cement strength

412 class $\left(f_{\text {cem }}\right)$ and water-to-cement ratio $(W / C)$, two technological parameters, 413 are key parameters for the determination of the concrete porosity and the 28 414 day compressive strength of concrete $\left(f_{c}\right)$ [9] [53]. Both values, indeed, are 415 important indicators of the evaluation of the resistance to penetration of 416 carbon dioxide into concrete [54]. Higher cement strength class $\left(f_{\text {cem }}\right)$ and a 417 decrease in water-to-cement ratio $(W / C)$ result in an increase of $f_{c}$. For a 418 given water-to-cement ratio $(W / C)$, it has been shown that service life $\left(t_{\text {ser }}\right)$ 419 increases by 1.89 times when using a CEM II/B cement with a cement 420 strength class $\left(f_{\text {cem }}\right)$ value about of $42.5 \mathrm{MPa}$ instead of $32.5 \mathrm{MPa}$ [55]. 421 Furthermore, the service life $\left(t_{\text {ser }}\right)$ increases by 2.49 times when using a 422 water-to-cement ratio $(W / C)$ of about 0.4 instead of 0.43 , according to the 
423 literature [56]. Previous experimental results [55] [56] have confirmed that

424 service life $\left(t_{\text {ser }}\right)$ is more sensitive to cement strength class $\left(f_{\text {cem }}\right)$ and water425 to-cement ratio $(W / C)$. In addition, a survey of the literature also reveals that 426 the carbonation resistance of concrete depends on the amount of Portland 427 clinker cement in concrete [57]. When using a cement preparation containing 428 more Portland clinker for concrete composition, first, the 28-day 429 compressive strength of concrete $\left(f_{c}\right)$ is higher and the amount of $\mathrm{Ca}(\mathrm{OH})_{2}$ 430 and $\mathrm{CSH}$ increases [58]. Both observations increase concrete carbonation 431 resistance. Finally, the other technological parameters considered here 432 demonstrate a negligible contribution to the variations of service life $\left(t_{\text {ser }}\right)$. 433 An increase in cement content $(C)$, obviously causes the presence of higher 434 amounts of Calcium hydroxide $\left(\mathrm{Ca}(\mathrm{OH})_{2}\right)$ and $\underline{\text { Calcium-Silicate- } \underline{H} y d r a t e}$ 435 (CSH) inside the concrete, which lengthens the time of the neutralization 436 reaction between $\mathrm{Ca}(\mathrm{OH})_{2}$ and $\mathrm{CSH}$ and $\mathrm{CO}_{2}$. The carbonation resistance is 437 thus higher. An increase in maximum aggregate size ( $S_{-}$max $)$generates a 438 decrease in the carbonation resistance. The use of a bigger aggregate size, 439 indeed, induces (i) a reduction in the tortuosity of the flow path, which 440 increases permeability, and (ii) a possibility of internal water bleeding, 441 which increases concrete porosity [59]. As regards the initial curing period $442\left(t_{c}\right)$, many previous studies [56] [60] [41] have underlined that the longer the 443 curing period is, the higher the resistance of concrete to carbonation is. An 444 increase in $t_{c}$ provides a higher degree of hydration and a lower concrete 445 porosity. As regards the concrete cover depth $(d)$, it is widely accepted that 446 service life $\left(t_{s e r}\right)$ is proportional to the square of concrete cover depth $(d)$ as 
447 shown in $E q$. (8). An increase in sand-to-gravel ratio $(S / G)$ in one cubic meter 448 of concrete mixed increases sand content, which is responsible for the 449 reduction in air permeability. There also, the carbonation resistance is 450 increased [59].

451 As regards the environmental parameters, previous experimental results 452 [23] [24] have shown that the highest carbonation rate is observed for a 453 relative external humidity $(R H)$ around $57 \%$. We observe that the carbonation 454 rate increases when relative external humidity $(R H)$ increases from $0 \%$ to $45557 \%$, and decreases when relative external humidity $(R H)$ increases from 57\% 456 to $100 \%$. This is consistent and corresponds to the highest $\sigma_{j} / \mu_{j}^{*}$ of relative 457 external humidity $(R H)$ (Figure 4) that is highlighted by the present 458 sensitivity analysis results. The carbonation rate also increases with 459 increasing ambient temperature $(T)$ due to increased molecular activity [61] 460 [62]. Finally, the carbonation depth is proportional to the square root of 461 carbon dioxide concentration in the air $\left(\mathrm{CO}_{2}\right)(E q .(7))$. The presence of 462 carbon dioxide is necessary for the carbonation of concrete. However, 463 relative external humidity $(R H)$ and ambient temperature $(T)$ play the most 464 important part in the carbonation rate within all the environmental 465 parameters.

466 The influence trend of parameters is consistent with the literature. The 467 important influence of parameters corresponding to their range variation 468 studied corroborates with previous experimental studies. 


\subsection{Final design}

470 Based on the $\mathrm{SA}$ results, the action levers of the case study are cement 471 strength class $\left(f_{\text {cem }}\right)$, water-to-cement ratio $(W / C)$ and cement type $(C E M)$.

472 The final design is carried out by setting the action lever at their most 473 favorable value to increase the service life $\left(t_{s e r}\right)$ (Table 2). As found 474 previously, the most favorable values of the three action levers consist of 475 minimum $W / C$ (about 0.4 ), higher $f_{\text {cem }} 52.5 \mathrm{MPa}$ and CEM I or CEM II/B 476 cement type (Figure 5). The other parameters are randomly generated 477 according to their PDF presented in Table 1. This scenario is called 478 recommended scenario.

479 A reference scenario, called EN 206-1 scenario, is also developed by setting 480 the action levers at the limiting values recommended by EN 206-1 [15], i.e., $481 W / C$ equal to $0.5, f_{\text {cem }} 32.5 \mathrm{MPa}$ and CEM I cement type (Table 2). The other 482 parameters are randomly generated according to their PDF as with the 483 recommended scenario.

484 We compare the distribution of $t_{\text {ser }}$ of EN 206-1 scenario and recommended 485 scenario with CEM I cement type in Figure 6. The recommended scenario 486 with CEM II/B cement type is not illustrated in Figure 6 as its $t_{\text {ser }}$ 487 distribution is very close to that of CEM I cement type. The mean $t_{\text {ser }}$ of 488 recommended scenario with CEM II/B cement type is of about 9,253 years. 489 The distribution of $t_{\text {ser }}$ is simulated using a Monte Carlo simulation with a 490 sample size of $100,000$. 
Table 2. Values of action levers for both designed scenarios.

\begin{tabular}{lcccc}
\hline Parameter & Symbol & Unit & $\begin{array}{c}\text { Recommended } \\
\text { scenario }\end{array}$ & $\begin{array}{c}\text { EN 206-1 } \\
\text { scenario }\end{array}$ \\
\hline Water-to-cement ratio & $W / C$ & n.u. & 0.4 & 0.5 \\
Cement strength class & $f_{\text {cem }}$ & MPa & 52.5 & 32.5 \\
Cement type & $C E M$ & n.u. & CEM I & CEM I \\
\hline
\end{tabular}

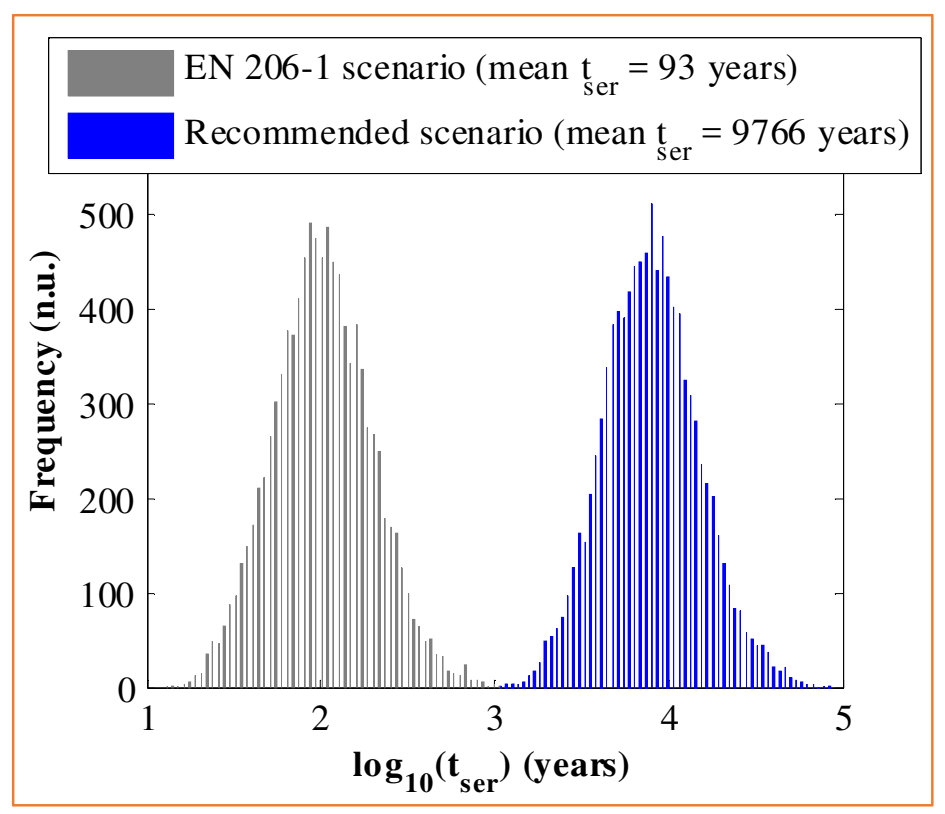
higher than that of the EN 206-1 scenario. Both distributions of probabilities 497 are completely separated. The calculated differences are significant. The 498 simulation results confirmed $f_{c e m}, W / C$ as being effective action levers. The recommended scenario corresponds to concrete with higher carbonation 500 resistance. We consider the high concrete cover depth $(d)$ between $0.05 \mathrm{~m}$ and $0.08 \mathrm{~m}$, that is another reason for finding the mean service life of the 
recommended scenario of about 9,766 years. This finding corroborates with

503 previously experimental results [4] [34] [35] [36]. For example, Houst et al.

504 [34] reveal that more than five years of exposure to the atmosphere of $\mathrm{CO}_{2}$,

505 concrete with $W / C=0.3$ is carbonated only to a depth of 0.2 to $0.3 \mathrm{~mm}$.

506 Another study on ultra-high performance fiber-reinforced concrete (porosity

507 about 5\%) [63] shows that the $t_{\text {ser }}$ is more than 12,000 years. One can assume

508 that this higher $t_{\text {ser }}$ is not only due to the individual influence of action levers

509 but also to the non-negligible interactions between the action levers and other

510 parameters (revealed previously through the differences $S_{T_{j}}-S_{j} \geq 10 \%$ ).

511 The simulation results of the recommended scenario reveal that a durable

512 RC structure can be obtained by setting the action levers at their most

513 favorable values. The durable RC structure is independent on the values of

514 the other technological parameters, which are simulated randomly within

515 their variability range given in Table 1 . In short, if the RC structure is

516 designed using the recommended scenario, the risk for corrosion of

517 reinforcing steels due to carbonation is eliminated throughout the 100 -year

518 service life design. In addition, concretes with $f_{\text {cem }} 52.5 \mathrm{MPa}$ and with $W / C$

519 of about 0.4 are appropriate for the other cement types (Figure 5). On the

520 contrary, if the RC structure is designed by setting the action levers at their

521 limiting values as recommended by EN 206-1 [15], a maintenance system

522 could be established in order to ensure the intended 100-year service life. 


\section{3.5. Advantages and limits of the design approach}

524 In this particular case, the cement content $(C)$ does not individually 525 contribute to service life (with $S_{j}$ around $1 \%$ ), i.e., the service life $\left(t_{s e r}\right)$ is 526 independent of cement content $(C)$ for a given water-to-cement ratio $(W / C)$.

527 A previous study has revealed that the carbonation of concrete is independent 528 of cement content $(C)$ (from 221 to $450 \mathrm{~kg} / \mathrm{m}^{3}$ ) for a given water-to-cement 529 ratio $(W / C)$ [64]. The present finding, achieved in association with the 530 literature, raises the problem of attempting to impose a minimum cement 531 content $(C)$ of $300 \mathrm{~kg} / \mathrm{m}^{3}$ for XC4 exposure class in EN 206-1 [15]. The model 532 developed does not consider that a high cement content $(C)$ may enhance the 533 risk of cracking because of the heat of hydration or the drying shrinkage in

534 the concrete cover. Both can result in a poor carbonation resistance of the 535 concrete cover. Furthermore, from the point of view of the environmental 536 impacts of the concrete, cement, among other constituents of concrete, is 537 mainly responsible for the release of a huge amount of $\mathrm{CO}_{2}$ during the 538 production [65]. Consequently, in the case of an XC4 exposure class, the 539 requirement for the minimum $C$ in EN 206-1 [15] should be re-examined 540 whereas a maximum limit of $C$ within the mix should also be specified.

541 Our approach is a helpful tool in the life cycle design for the durability of

542 RC structures. Our approach aims identifying action levers for increasing 543 service life. Engineering designers easily increase the service life by 544 focusing on effective action levers. 
545 Results of our case study are related both to the carbonation model chosen

546 and to PDF of input parameters. If we use another range variability of input

547 parameters, our results would be changed [66]. However, our approach is

548 general and can be adapted to various service life models.

549 In this study, carbonation is the only alteration phenomenon of RC structure

550 that is considered. However, concrete carbonation can be coupled with other

551 severe deteriorations leading to accelerate its degradation, e.g., the presence

552 of a small amount of chlorides significantly increases the corrosion risk in 553 carbonated mortars [67]. In that situation, the combined effects of various 554 alteration mechanisms integrated in service life model.

555 Finally, this study focuses on individual input parameters that are action 556 levers on the improvement of service life of RC structures. However, 557 interactions between two or more input parameters were shown to be also 558 influential on service life prediction and merit further investigations.

559 4. Summary and conclusion

560 The present study was conducted to develop a new design procedure for the 561 durability of $\mathrm{RC}$ structures through resistance to carbonation induced 562 corrosion. This innovative approach consists in combining the techniques of 563 the prescriptive and performance-based approaches and in integrating the 564 sensitivity analysis of service life in the design stage. The durability design 565 phase has focused on the most influential parameters with a view to setting 
566 them at their most favorable value. With suitable calculation tools, this

567 proposed procedure will be easy to use by designers.

568 Through the case study presented here, we found that cement strength class $569\left(f_{\text {cem }}\right)$, water-to-cement ratio $(W / C)$ and cement type $(C E M)$ are action levers.

570 Design engineers may take these action levers carefully into account during 571 the durability design step of concrete exposed to carbonation. When setting 572 the action levers at their most favorable values instead of their limiting 573 values as recommended by EN 206-1, the service life is significantly 574 improved. The requirement for minimum cement content $(C)$ in EN 206-1 for $575 \mathrm{XC} 4$ exposure class should be re-examined in order to reduce concrete costs 576 and environmental impacts. The most influential parameters, including $W / C$, $577 f_{\text {cem }}, C E M$, ambient temperature $(T)$ and relative external humidity $(R H)$, 578 should therefore be carefully considered in future research works conducted 579 to address the problem of carbonation-induced corrosion damage modeling 580 in RC structures.

581 More research work needs to be carried out to investigate the interaction 582 influences between the parameters. For instance, in the case study presented, 583 the identified action levers have strong interactions with the other 584 parameters. These interactions, however, have not been examined here. The 585 results of studies addressing the problem of interactions between parameters 586 could additionally enhance the durability of RC structures. We are confident 587 that this finding will serve as a basis for future theoretical and experimental 588 works. 


\section{Acknowledgements}

590 Funds for the research and education chair of civil engineering and eco-

591 construction were provided by the Chamber of Trade and Industry of Nantes

592 and Saint-Nazaire cities, the CARENE (urban agglomeration of Saint-

593 Nazaire), Charier, Architectes Ingénieurs Associés, Vinci construction, the

594 Regional Federation of Buildings, and the Regional Federation of Public

595 Works. Donators have had no involvement in the research design, the writing

596 and the decision to submit this article. The authors would like to thank them

597 all for their financial support. 


\section{Reference}

599

600

601

602

603

604

605

606

607

608

609

610

611

612

613

614

615

616

617

618

619

620

621

622

623

624

625

626

627

628

629

630

631

632

[1] P. F. Marques, C. Chastre, and Â. Nunes, "Carbonation service life modelling of RC structures for concrete with Portland and blended cements," Cem. Concr. Compos., vol. 37, pp. 171-184, Mar. 2013.

[2] EN 1990, "Eurocode - Basis of structural design." European committee for standardization, 2002.

[3] A. Sarja, "Durability design of concrete structures-Committee report 130-CSL," Mater. Struct., vol. 33, no. 1, pp. 14-20, 2000.

[4] fib CEB-FIP, Ed., Model code for service life design. Lausanne: fib, 2006.

[5] K. Y. Ann, S.-W. Pack, J.-P. Hwang, H.-W. Song, and S.-H. Kim, "Service life prediction of a concrete bridge structure subjected to carbonation," Constr. Build. Mater., vol. 24, no. 8, pp. 1494-1501, Aug. 2010 .

[6] A. Duan, J.-G. Dai, and W. Jin, "Probabilistic approach for durability design of concrete structures in marine environments," J. Mater. Civ. Eng., vol. 27, no. 2, 2015.

[7] Q. Li, K. Li, X. Zhou, Q. Zhang, and Z. Fan, "Model-based durability design of concrete structures in Hong Kong-Zhuhai-Macau sea link project," Struct. Saf., vol. 53, pp. 1-12, Mar. 2015.

[8] P. C. Ryan and A. J. O'Connor, "Probabilistic analysis of the time to chloride induced corrosion for different Self-Compacting Concretes," Constr. Build. Mater., vol. 47, pp. 1106-1116, Oct. 2013.

[9] L. Bertolini, "Steel corrosion and service life of reinforced concrete structures," Struct. Infrastruct. Eng., vol. 4, no. 2, pp. 123-137, Apr. 2008.

[10] "Sensitivity Analysis - EU Science Hub - European Commission," EU Science Hub, 12-May-2015. [Online]. Available: https://ec.europa.eu/jrc/en/samo. [Accessed: 16-Nov-2016].

[11] J. Zhang and Z. Lounis, "Sensitivity analysis of simplified diffusionbased corrosion initiation model of concrete structures exposed to chlorides," Cem. Concr. Res., vol. 36, no. 7, pp. 1312-1323, Jul. 2006.

[12] A. Boddy, E. Bentz, M. D. A. Thomas, and R. D. Hooton, "An overview and sensitivity study of a multimechanistic chloride transport model," Cem. Concr. Res., vol. 29, no. 6, pp. 827-837, 1999. 
649

650

651

652

653

654

655

656

657

658

659

660

661

662

663

664

665

666

667

668

669

[13] K. Siamphukdee, F. Collins, and R. Zou, "Sensitivity Analysis of Corrosion Rate Prediction Models Utilized for Reinforced Concrete Affected by Chloride," J. Mater. Eng. Perform., vol. 22, no. 6, pp. 15301540, Jun. 2013.

[14] N. R. Ravahatra, T. De Larrard, F. Duprat, E. Bastidas-Arteaga, and F. Schoefs, "Sensitivity analysis of simplified models of carbonationextension in spatial variability-updating through Bayesian network," in Proceedings of the 2nd International Symposium on Uncertainty Quantification and Stochastic Modeling, 2014.

[15] European Standard EN 206-1, "Concrete-Part 1: Specification, performance, production and conformity." 2007.

[16] I. M. Sobol, "Global sensitivity indices for nonlinear mathematical models and their Monte Carlo estimates," Math. Comput. Simul., vol. 55, no. 1, pp. 271-280, 2001.

[17] M. D. Morris, "Factorial Sampling Plans for Preliminary Computational Experiments," Technometrics, vol. 33, no. 2, pp. 161-174, May 1991.

[18] Andrianandraina, A. Ventura, T. Senga Kiessé, B. Cazacliu, R. Idir, and H. M. G. van der Werf, "Sensitivity Analysis of Environmental Process Modeling in a Life Cycle Context: A Case Study of Hemp Crop Production: Environmental Process Modeling in a Life Cycle Context," J. Ind. Ecol., vol. 19, no. 6, pp. 978-993, Dec. 2015.

[19] T. Senga Kiessé, A. Ventura, H. M. G. van der Werf, B. Cazacliu, R. Idir, and Andrianandraina, "Introducing economic actors and their possibilities for action in LCA using sensitivity analysis: Application to hemp-based insulation products for building applications," J. Clean. Prod., Oct. 2016.

[20] T. Homma and A. Saltelli, "Importance measures in global sensitivity analysis of nonlinear models," Reliab. Eng. Syst. Saf., vol. 52, pp. 1-17, 1996.

[21] F. Campolongo, J. Cariboni, and A. Saltelli, "An effective screening design for sensitivity analysis of large models," Environ. Model. Softw., vol. 22, no. 10, pp. 1509-1518, Oct. 2007.

[22] A. Saltelli, S. Tarantola, and M. Ratto, Sensitivity analysis in pratice: A guide to assessing scientific models, WILEY. 2004.

[23] L. De Ceukelaire and D. Van Nieuwenburg, "Accelerated carbonation of a blast-furnace cement concrete," Cem. Concr. Res., vol. 23, pp. 442$452,1993$. 
690

691

692

693

694

695

696

697

698

699

700

701

702

703

[24] B. G. Salvoldi, H. Beushausen, and M. G. Alexander, "Oxygen permeability of concrete and its relation to carbonation," Constr. Build. Mater., vol. 85, pp. 30-37, Jun. 2015.

[25] "Fifth Assessment Report - Climate Change 2013." [Online]. Available: http://www.ipcc.ch/report/ar5/wg1/. [Accessed: 18-Jan-2017].

[26] "Weather Data I EnergyPlus." [Online]. Available: https://energyplus.net/weather. [Accessed: 06-May-2016].

[27] K. Tuutti, "Corrosion of steel in concrete," Swedish Cement and Concrete Research Institute, ISSN 0346-6906, Stockholm, Sweden, 1982.

[28] V.-L. Ta, S. Bonnet, T. Senga Kiesse, and A. Ventura, "A new metamodel to calculate carbonation front depth within concrete structures," Constr. Build. Mater., vol. 129, pp. 172-181, Dec. 2016.

[29] V. G. Papadakis, "A reaction engineering approach to the problem of concrete carbonation," AIChE J., vol. 35, no. 10, pp. 1639-1650, 1989.

[30] K.-H. Yang, E.-A. Seo, and S.-H. Tae, "Carbonation and CO2 uptake of concrete," Environ. Impact Assess. Rev., vol. 46, pp. 43-52, Apr. 2014.

[31] P. F. Marques and A. Costa, "Service life of RC structures: Carbonation induced corrosion. Prescriptive vs. performance-based methodologies," Constr. Build. Mater., no. 24, pp. 258-265, 2010.

[32] British Standards Institution, Concrete--complementary British Standard to BS EN 206-1. Part 1, Part 1,. London: BSI, 2006.

[33] LNEC E465, "Concrete. Methodology for estimating the concrete performence properties allowing to comply with the design working life of the reinforced or pre-stressed concrete structures under environmental exposures XC and XS.” Lisbon: LNEC, 2007.

[34] Y. F. Houst and F. H. Wittmann, "Influence of porosity and water content on the diffusivity of $\mathrm{CO} 2$ and $\mathrm{O} 2$ through hydrated cement paste," Cem. Concr. Res., vol. 24, no. 6, pp. 1165-1176, 1994.

[35] V. T. Ngala and C. L. Page, "Effects of carbonation on pore structure and diffusional properties of hydrated cement pastes," Cem. Concr. Res., vol. 27 , no. 7, pp. 995-1007, 1997.

[36] IS 456: 2000, "Plain and reinforced concrete-code of practice." Bureau of indian standards 2000, 2000. 
[37] S.-J. Kwon, S.-S. Park, and S.-H. Nam, "A suggestion for carbonation prediction using domestic field survey data of carbonation," J. Korea Inst. Struct. Maint. Insp., vol. 11, no. 5, pp. 81-88, 2007.

[38] E. Rozière, A. Loukili, and F. Cussigh, "A performance based approach for durability of concrete exposed to carbonation," Constr. Build. Mater., vol. 23, no. 1, pp. 190-199, Jan. 2009.

[39] I. Galan, C. Andrade, P. Mora, and M. A. Sanjuan, "Sequestration of CO2 by concrete carbonation," Environ. Sci. Technol., vol. 44, no. 8, pp. 3181-3186, 2010.

[40] B. Chatveera and P. Lertwattanaruk, "Durability of conventional concretes containing black rice husk ash," J. Environ. Manage., vol. 92, no. 1, pp. 59-66, Jan. 2011.

[41] A. Durán-Herrera, J. M. Mendoza-Rangel, E. U. De-Los-Santos, F. Vázquez, P. Valdez, and D. P. Bentz, "Accelerated and natural carbonation of concretes with internal curing and shrinkage/viscosity modifiers," Mater. Struct., vol. 48, no. 4, pp. 1207-1214, Apr. 2015.

[42] J. B. Aguiar and C. Júnior, "Carbonation of surface protected concrete," Constr. Build. Mater., vol. 49, pp. 478-483, Dec. 2013.

[43] S. Talukdar, N. Banthia, and J. R. Grace, "Carbonation in concrete infrastructure in the context of global climate change - Part 1: Experimental results and model development," Cem. Concr. Compos., vol. 34, no. 8, pp. 924-930, Sep. 2012.

[44] P. Dinakar, K. G. Babu, and M. Santhanam, "Corrosion behaviour of blended cements in low and medium strength concretes," Cem. Concr. Compos., vol. 29, no. 2, pp. 136-145, Feb. 2007.

[45] M. R. Jones, M. D. Newlands, A. M. O. Abbas, and R. K. Dhir, "Comparison of 2 year carbonation depths of common cement concretes using the modified draft CEN test," Mater. Struct., vol. 34, no. 7, pp. 396-403, 2001.

[46] G. De Schutter and K. Audenaert, "Evaluation of water absorption of concrete as a measure for resistance against carbonation and chloride migration," Mater. Struct., vol. 37, pp. 591-596, 2004.

[47] B. Bary and A. Sellier, "Coupled moisture-carbon dioxide-calcium transfer model for carbonation of concrete," Cem. Concr. Res., vol. 34, no. 10, pp. 1859-1872, Oct. 2004.

[48] M. Thiery, G. Villain, P. Dangla, and G. Platret, "Investigation of the carbonation front shape on cementitious materials: Effects of the 
chemical kinetics," Cem. Concr. Res., vol. 37, no. 7, pp. 1047-1058, Jul. 2007.

[49] H. Cui, W. Tang, W. Liu, Z. Dong, and F. Xing, "Experimental study on effects of $\mathrm{CO} 2$ concentrations on concrete carbonation and diffusion mechanisms," Constr. Build. Mater., vol. 93, pp. 522-527, Sep. 2015.

[50] A. Leemann, P. Nygaard, J. Kaufmann, and R. Loser, "Relation between carbonation resistance, mix design and exposure of mortar and concrete," Cem. Concr. Compos., vol. 62, pp. 33-43, Sep. 2015.

[51] EN 197-1, “Cement-Part 1: Composition, specifications and conformity criteria for common cements." 2002.

[52] NF EN 1992-1-1/NA, "Eurocode 2: Calcul des structures en béton Partie 1-1: Règles générales et règles pour les bâtiments," 2007.

[53] S. E. Chidiac, F. Moutassem, and F. Mahmoodzadeh, "Compressive strength model for concrete," Mag. Concr. Res., vol. 65, no. 9, pp. 557572, May 2013.

[54] M. I. Khan and C. J. Lynsdale, "Strength, permeability, and carbonation of high-performance concrete," Cem. Concr. Res., vol. 32, no. 1, pp. $123-131,2002$.

[55] M. Valcuende and C. Parra, "Natural carbonation of self-compacting concretes," Constr. Build. Mater., vol. 24, no. 5, pp. 848-853, May 2010 .

[56] Y. Jia, B. Aruhan, and P. Yan, "Natural and accelerated carbonation of concrete containing fly ash and GGBS after different initial curing period," Mag. Concr. Res., vol. 64, no. 2, pp. 143-150, février 2012.

[57] N. Hyvert, A. Sellier, F. Duprat, P. Rougeau, and P. Francisco, "Dependency of $\mathrm{C}-\mathrm{S}-\mathrm{H}$ carbonation rate on $\mathrm{CO} 2$ pressure to explain transition from accelerated tests to natural carbonation," Cem. Concr. Res., vol. 40, no. 11, pp. 1582-1589, Nov. 2010.

[58] V. G. Papadakis, "Effect of supplementary cementing materials on concrete resistance against carbonation and chloride ingress," Cem. Concr. Res., vol. 30, no. 2, pp. 291-299, 2000.

[59] L. Basheer, P. A. M. Basheer, and A. E. Long, "Influence of coarse aggregate on the permeation, durability and the microstructure characteristics of ordinary Portland cement concrete," Constr. Build. Mater., vol. 19, no. 9, pp. 682-690, Nov. 2005. 
802

803

[60] J. P. Balayssac, C. H. Détriché, and J. Grandet, "Effects of curing upon carbonation of concrete," Constr. Build. Mater., vol. 9, no. 2, pp. 9195, 1995.

[61] M. A. Sanjuán and R. Muñoz-Martialay, "Influence of the water/cement ratio on the air permeability of concrete," J. Mater. Sci., vol. 31, no. 11, pp. 2829-2832, 1996.

[62] G. Yuan and Q. Li, "The use of surface coating in enhancing the mechanical properties and durability of concrete exposed to elevated temperature," Constr. Build. Mater., vol. 95, pp. 375-383, Oct. 2015.

[63] InfoCIMENTS, "Les Bétons Fibrés à Ultra hautes Performances BFUP." .

[64] R. Wassermann, A. Katz, and A. Bentur, "Minimum cement content requirements: a must or a myth?," Mater. Struct., vol. 42, no. 7, pp. 973982, Aug. 2009.

[65] M. Nisbet, M. G. Van Geem, and M. Marceau, "Environmental life cycle inventory of Portland cement and concrete." Portland Cement Association, 2002.

[66] P. Heiselberg, H. Brohus, A. Hesselholt, H. Rasmussen, E. Seinre, and S. Thomas, "Application of sensitivity analysis in design of sustainable buildings," Renew. Energy, vol. 34, no. 9, pp. 2030-2036, Sep. 2009.

[67] G. K. Glass, C. L. Page, and N. R. Short, "Factors affecting the corrosion rate of steel in carbonated mortars," Corros. Sci., vol. 32, no. 12, pp. 1283-1294, 1991.

[68] R. Folic, "Durability design of concrete structures, Part 1: Analysis fundamentals," Facta Univ. - Ser. Archit. Civ. Eng., vol. 7, no. 1, pp. 1$18,2009$.

\section{Appendix: Definitions}

Durability is the ability to maintain the serviceability of a structure over a specified length of time, or a characteristic of the structure to function for a given period with required safety and corresponding characteristics providing serviceability [68]. 
808 Durability design makes sure that service life design can be completed in

809 the actual local exposure conditions during the design stage.

810 Service life design is the service life that the designer intends for the 811 structures undergoing expected aggressions and service maintenance

812 according to a prescribed maintenance management strategy.

813 Service life is the period after construction, during which all the structure 814 properties, when routinely maintained, are higher than the minimum 815 acceptable values [2].

816 Technological parameters are controllable parameters (i.e. action

817 possibilities). They are related to the technological aspects (e.g., concrete 818 mix, size of structure).

819 Environmental parameters are uncontrollable parameters. They are 820 related to the environmental open-air location (e.g., aggressive agent sources 821 like $\mathrm{CO}_{2}$ concentration, chlorides, ambient temperature, and relative 822 humidity).

823 Action levers are the technological parameter, which are major contributors 824 to the sensitive service life. They are determined by carrying out a sensitivity 825 analysis of the service life prediction model.

826 Table A1. Cement type characterization.

\begin{tabular}{lccc}
\hline Cement type & Clinker (n.u.) & CaO (n.u.) & Cement density $\left(\mathbf{k g} / \mathrm{m}^{\mathbf{3}}\right)$ \\
\hline CEM I & 0.98 & 0.64 & 3110
\end{tabular}




\begin{tabular}{lccl} 
CEM II/A & 0.87 & 0.62 & 3000 \\
CEM II/B & 0.72 & 0.46 & 3005 \\
CEM III/A & 0.5 & 0.53 & 2880 \\
CEM III/B & 0.27 & 0.48 & 2850 \\
CEM III/C & 0.12 & 0.46 & 2750 \\
CEM IV/A & 0.77 & 0.38 & 2980 \\
CEM IV/B & 0.55 & 0.31 & 2890 \\
CEM V/A & 0.52 & 0.47 & 2870 \\
CEM V/B & 0.3 & 0.47 & 2870 \\
\hline
\end{tabular}

827 